\title{
PENGARUH KREDIT TERHADAP KESEJAHTERAAN PETANI CABAI RAWIT MERAH DI KABUPATEN TASIKMALAYA
}

\author{
THE EFFECT OF CREDIT ON THE WELFARE OF CAYENNE PEPPER \\ IN TASIKMALAYA DISTRICT
}

\author{
Anisa Puspitasari*, Saepul Aziz, Ane Novianty \\ Fakultas Pertanian Universitas Galuh \\ *Email : nisapuspita253@gmail.com \\ (Diterima 02-07-2021; Disetujui 22-07-2021)
}

\begin{abstract}
ABSTRAK
Barang-barang pertanian yang termasuk barang modal dapat berupa uang, tanah, pupuk, investasi dalam mesin. Kredit berperan sebagai penambah modal untuk membiayai input produksi sehingga produsen dapat meningkatkan produknya pada tingkat yang lebih tinggi, cabai merupakan salah satu komoditi yang mempunyai prospek cerah guna menambah pendapatan para petani penelitian ini bertujuan untuk melihat bagaimana kesejahteraan petani cabai di Kabupaten Tasikmalaya terhadap kredit yang ada di daerah tersebut.Teknik pengambilan sampel dengan menggunakan teknik accidental sampling adalah teknik penentuan sampel berdasarkan kebetulan yaitu siapa saja yang bertemu secara kebetulan dengan peneliti dapat digunakan sampel, bila petani yang ditemui cocok sebagai sumber data. Karena jumlah populasi yang terlalu banyak dan penulis mempunyai keterbatasan waktu, dana, serta tenaga, maka sampel dalam penelitian ini ditentukan secara sengaja yaitu 30 responden dari semua petani cabai rawit yang menggunakan kredit untuk pertaniannya. Teknik analisis yang dilakukan menggunakan analisis regresi linier berganda, dimana data diolah dengan menggunakan SPSS. Hasil dari penelitian ini menunjukkan Koefisien regresi modal sendiri (X1) -493 mempunyai pengaruh negatif terhadap perubahan tingkat pendapatan, namun tidak signifikan. Koefisien regresi pinjaman kredit pertanian (X2) 566 mempunyai pengaruh positif terhadap perubahan tingkat pendapatan dan signifikan. Dari hasil perhitungan koefisen regresi luas lahan (X3) 183.866 bahwa besarnya pengaruh variable bebas X3 (luas lahan) terhadap perubahan tingkat pendapatan petani cabai berpengaruh positif. Kesimpulan dari penelitian ini petani cabai yang melakukan pinjaman kredit diharapkan dapat membangun atau meningkatkan pendapatan dan tingkat kesejahteraan para debiturnya yang berasal dari sektor pertanian.
\end{abstract}

Kata kunci: kredit, cabai rawit merah, kesejahteraan, petani

\begin{abstract}
Agricultural goods which include capital goods can be in the form of money, land, fertilizer, investment in machinery. Credit acts as a capital increase to finance production inputs so that producers can increase their products at a higher level, chili is one of the commodities that have bright prospects to increase farmers' income. in the area. The sampling technique using the accidental sampling technique is a sampling technique based on chance, ie anyone who meets by chance with the researcher can be used as a sample, if the farmer met is suitable as a data source Because the population is too large and the author has limited time, funds, and energy, the sample in this study was deliberately determined, namely 30 respondents from all cayenne pepper farmers who use credit for their agriculture. The analysis technique is carried out using multiple linear regression analysis, where the data is processed using SPSS. The results of this study indicate the regression coefficient of equity (XI) -493 has a negative effect on changes in income levels, but not significant. The regression coefficient for agricultural credit loans (X2) 566 has a positive and significant effect on changes in income levels. From the results of the calculation of the regression
\end{abstract}


coefficient of land area (X3) 183,866 that the magnitude of the influence of the independent variable X3 (land area) on changes in the income level of chili farmers has a positive effect. The conclusion of this study is that chili farmers who make credit loans are expected to build or increase the income and welfare level of their debtors from the agricultural sector.

Keywords: credit, cayenne pepper, welfare, farmers

\section{PENDAHULUAN}

Indonesia adalah negara dengan sebagian besar penduduknya bermata pencaharian sebagai petani. Mayoritas petani-petani di Indonesia memiliki pendapatan yang sangat rendah, sehingga kehidupan petani-petani tersebut jauh dari kata sejahtera. Hal ini dapat disebabkan oleh susahnya para petani dalam memperoleh permodalan untuk meningkatkan produksi mereka, sehingga berdampak pada pendapatan yang diperoleh. (Anshory, 2018).

Pendapatan rendah adalah sumber dari terjadinya kemiskinan. Pendapatan petani rendah dikarenakan rendahnya produktifitas sebagai akibat dari rendahnya tingkat adopsi teknologi. Menurut Soekartiwi (2005), kesulitan dalam mengakses pembiayaan kredit karena terkendalanya dari kepemilikan aset, terutama lahan sebagai collateral.

Pertanian (agriculture) tidak hanya sebuah cara hidup (way of life atau lifehood) bagi sebagian petani Indonesia, lebih dari itu pertanian merupakan aktivitas ekonomi untuk menghasilkan pendapatan usaha pertaniannya, petani membutuhkan modal (capital) untuk mengelola dan mengembangkan usaha taninya. Modal tersebut biasanya didapat dari pinjaman kredit, baik di Bank, Koprasi Simpan Pinjam (KPS), atau koprasi kredit (KOPDIT).

Kredit berperan sebagai penambah modal untuk membiayai input produksi sehingga produsen dapat meningkatkan produknya pada tingkat yang lebih tinggi (Baker, 1986). Diasumsikan petani mengalami keterbatasan modal sehingga tidak mampu menggunakan input pada kondisi yang optimal, sehingga dengan adanya kredit sebagai tambahan modal mampu meningkatkan penggunaan input. Beberapa hasil penelitian menunjukkan ketersediaan kredit memberi kesempatan bagi petani untuk membeli input atau modal lainnya, yang pada akhirnya akan meningkatkan produksi dan pendapatan.

Modal adalah barang dan jasa yang bersama-sama dengan faktor produksi tanah dan tenaga kerja yang menghasilkan barang-barang baru. Barang-barang pertanian yang termasuk barang modal dapat berupa uang, tanah, pupuk, investasi dalam mesin, dan lain- 
lain. Biasanya semakin besar dan semakin baik kualitas modal yang dimiliki maka akan sangat mendukung terhadap peningkatan produksi yang dihasilkan. Maka secara jelas bahwa modal merupakan faktor yang utama untuk menentukan arah perkembangan pertanian. (Soekartiwi, 2003).

Cabai adalah komoditas sayuran penting yang dibudidayakan dalam pemenuhan kebutuhan gizi masyarakat Indonesia, baik sebagai komoditas yang dikonsumsi di dalam negeri dan ekspor. Cabai merupakan salah satu komoditi yang mempunyai prospek cerah guna menambah pendapatan para petani. Hal tersebut dapat memberi motivasi tersendiri bagi petani untuk lebih mengembangkan dan meningkatkan produksinya dengan harapan agar pada saat panen usaha memperoleh hasil penjualan tinggi, guna memenuhi kebutuhannya. Namun terkadang kenyataannya ketika panen tiba, hasil melimpah tetapi harga mendadak turun, dan lebih parah lagi jika hasil produksi yang telah diprediksikan jauh dari perkiraan jumlah produksi yang dihasilkan, produksi minim, harga rendah dan tidak menentu membuat petani cabai kadang merasa kecewa untuk tetap mengembangkan usaha pertaniannya. Hal ini disebabkan karena setiap kegiatan pengolahan mutlak petani mengeluarkan biaya untuk kegiatan produksi, mulai dari pengadaan bibit, pupuk, pengolahan, pestisida dan biaya lainnya yang tidak terduga.

Jawa Barat adalah salah satu dari beberapa provinsi di Indonesia yang menjadi produsen cabai yang menyebar di beberapa kabupaten yakni Ciamis, Tasikmalaya, Bandung, Garut, Sukabumi, Cianjur dan Bogor. Menurut Kustiari, dkk (2009), faktor-faktor yang mempengaruhi fluktuasi harga di pasar eceran, yaitu faktor yang mempengaruhi sisi permintaan dan faktor yang mempengaruhi sisi penawaran. Dapat dijelaskan bahwa kadang-kadang keseimbangan harga terjadi pada kondisi jumlah yang ditawarkan relatif jauh lebih sedikit dibandingkan dengan jumlah yang diminta. Hal inilah yang mengakibatkan harga akan sangat tinggi. Demikian pula terjadi sebaliknya sehingga harga sangat rendah.

Hal ini yang mendasari pentingnya dilakukan penelitian ini yang bertujuan untuk melihat bagaimana kesejahteraan petani cabai di Kabupaten Tasikmalaya terhadap kredit yang ada di daerah tersebut dengan mengakaji lebih lanjut faktor-faktor yang mempengaruhi 
kesejahteraan petani. Selain itu, pemberian kredit sebagai tambahan modal diharapkan akan membantu petani cabai di daerah penelitian untuk mengembangkan usahanya dan sekaligus dapat berdampak pada peningkatan pendapatan melalui peningkatan produksi. Namun, dapat dimungkinkan adanya penggunaan kredit justru tidak memberikan pengaruh yang signifikan terhadap pendapatan petani. Hal itu dapat terjadi dikarenakan dari segi pemanfaatan kredit yang belum tepat. Terlebih lagi jika kredit tersebut dibatasi jumlahnya (sedikit nilainya), tidak sesuai dengan ekonomi usahatani sehingga tidak memperlihatkan pengaruh yang signifikan pada peningkatan pendapatan (Ibrahim, 2013).

\section{METODE PENELITIAN}

Penelitian ini dilakukan di daerah Kabupaten Tasikmalaya dengan melakukan observasi ke daerah pengahasil cabai rawit dengan produksi kontribusi setiap tahunnya. Dapat dilihat pada Tabel 1.

Populasi dalam penelitian ini adalah semua petani cabai rawit yang menerima kredit pertanian berdasarkan luas lahan pertaniannya di Kabupaten Tasikmalaya.
Tabel 1. Produksi Cabai Rawit

\begin{tabular}{clc}
\hline No & Kecamatan & Produksi (ton/tahun) \\
\hline 1 & Cigalontang & 2.458 \\
2 & Kadipaten & 2.305 \\
3 & Taraju & 1.432 \\
\hline 4 & Sukaraja & 2.305 \\
\hline 5 & Sukahening & 1.432 \\
\hline
\end{tabular}

Sumber: BPS (2019)

Teknik pengambilan sampel dengan menggunakan teknik accidental sampling adalah teknik penentuan sampel berdasarkan kebetulan yaitu siapa saja yang bertemu secara kebetulan dengan peneliti dapat digunakan sampel, bila petani yang ditemui cocok sebagai sumber data. Menurut Arikunto (1999), apabila populasi kurang dari 100 maka semua akan menjadi sampel. Jika populasi lebih dari 100 maka akan diambil 5\% - 10\% atau 20\% - 25\% dari jumlah populasi. Karena jumlah populasi yang terlalu banyak dan penulis mempunyai keterbatasan waktu, dana, serta tenaga, maka sampel dalam penelitian ini ditentukan secara sengaja yaitu 30 responden dari semua petani cabai rawit yang menggunakan kredit untuk pertaniannya.

Jenis data yang diperlukan dalam penelitian ini adalah jenis data primer dan sekunder. Data primer diperoleh dari hasil penelitian secara empiris melalui penyebaran kuesioner terhadap 30 responden yaitu petani yang menerima 
kredit untuk mengolah lahan pertaniannya di Kabupaten Tasikmalaya.

Teknik analisis yang dilakukan menggunakan analisis regresi linier berganda, dimana data diolah dengan menggunakan program komputer SPSS. Metode analisis regresi linier berganda berfungsi untuk mengetahui pengaruh atau hubungan variabel bebas dengan variabel terikat. Nilai Y dapat diperoleh dengan rumus:

$$
Y=\alpha+\beta 1 X 1+\beta 2 X 2+\beta 3 X 3+\varepsilon
$$

Keterangan :

$\mathrm{Y}=$ Tingkat pendapatan atau tingkat

Kesejahteraan petani cabai rawit.

$\alpha=$ Konstanta (bilangan yg nilainya tetap)

$\mathrm{X} 1=$ Modal sendiri

$\mathrm{X} 2=$ Pinjaman kredit pertanian

X3 = Luas lahan (ha)

$\beta 123=$ Koefisien regresi

$\mathrm{e}=$ Kesalahan penduga

\section{HASIL DAN PEMBAHASAN}

\section{Identitas responden}

Petani responden pada penelitian ini adalah petani yang menanam cabai rawit merah yang melakukaan pinjaman modal kepada bank. Responden petani diambil di Kabupaten Tasikmalaya dengan pengambilan responden berdasarkan kebetulan yaitu siapa saja petani yang bertemu dan memenuhi syarat. Indikator yang digunakan dalam mengidentifikasi responden adalah umur, lama bertani, usaha lain petani, penggunaan kredit, dan hambatan perolehan kredit, dan perubahan pendapatan petani.

Tabel 2. Hubungan usia responden dan lama Bertani

\begin{tabular}{cccccc}
\hline \multicolumn{5}{c}{ Hubungan responden dengan lama bertani } \\
\hline Usia & $0-5$ & $6-10$ & $11-15$ & $16-20$ & $\begin{array}{c}\text { Jumlah } \\
\text { responden }\end{array}$ \\
\cline { 2 - 5 } & 2 & 0 & 0 & 0 & 2 \\
$31-40$ & 2 & 2 & 2 & 0 & 6 \\
$41-50$ & 5 & 5 & 4 & 0 & 10 \\
$51-60$ & 2 & 1 & 2 & 2 & 11 \\
$61-75$ & 0 & 0 & 0 & 1 & 1 \\
\hline Jumlah & 11 & 8 & 8 & 3 & 30 \\
responden & & & & \\
\hline
\end{tabular}

Sumber: Data primer diolah 2021.

Pada table 1 menunjukkan responden paling banyak pada usia 41-50 tahun dengan lama bertani 6-10 tahun. Usia petani masih tergolong produktif dengan pengalaman yang cukup lama sehingga petani dapat meningkatkan hasil produksinya.

$$
\text { Menurut Andrie }
$$
kemampuan petani dalam mengelola usahatani seiring semakin produktif umurnya maka mempunyai kecenderungan bertambah pula kemampuan dalam mengelola usahataninya ke tingkat yang lebih berhasil dan berkembang ke arah yang lebih maju. 
Tabel.3 Hubungan antara usaha lain dengan kebutuhan hidup

\begin{tabular}{|c|c|c|c|c|c|c|}
\hline \multirow{2}{*}{ Usaha lain } & \multicolumn{5}{|c|}{ Kebutuhan hidup } & \multirow{2}{*}{$\begin{array}{c}\text { Jumlah } \\
\text { Responden }\end{array}$} \\
\hline & $\mathrm{ST}$ & $\mathrm{T}$ & $\mathrm{C}$ & $\mathrm{K}$ & SK & \\
\hline Tidak Ada & 2 & 0 & 6 & 1 & 0 & 9 \\
\hline Bertani Padi & 3 & 1 & 4 & 3 & 2 & 13 \\
\hline Warung & 0 & 0 & 4 & 0 & 0 & 4 \\
\hline Lainnya & 0 & 0 & 4 & 0 & 0 & 4 \\
\hline $\begin{array}{l}\text { Jum } \\
\text { Responden }\end{array}$ & 5 & 1 & 18 & 4 & 2 & 30 \\
\hline
\end{tabular}

Sumber : Data primer diolah, 2021

Tabel 3 menunjukkan bahwa hubungan antara usaha lain dengan kebutuhan hidup dari responden dapat diketahui lebih banyak kebutuhan hidupnya cukup dan memiliki usaha lain selain bertani cabai sedangkan kebutuhan hidupnya yang masih sangat kurang terdapat 2 responden walaupun sudah memiliki lahan untuk bertani cabai. Hal ini disebabkan penggunaan pinjaman kredit belum maksimal seluruhnya untuk pengelolaan budidaya cabai rawit.

Tabel 4. Persentase penggunaan kredit dengan penggunaan lainnya.

\begin{tabular}{lrrrrr} 
& Perolehan & \multicolumn{2}{c}{ Hambatan } & \multicolumn{2}{c}{$\begin{array}{c}\text { Jumlah } \\
\text { Redit }\end{array}$} \\
\cline { 2 - 5 } & Agunan & Lama Waktu & Syarat Pendukung & Bertele-tele & Responden \\
\hline Sulit & 0 & 3 & 4 & 6 & 13 \\
Biasa & 0 & 2 & 3 & 5 & 10 \\
Mudah & 2 & 4 & 0 & 0 & 6 \\
Sangat Mudah & 0 & 0 & 1 & 0 & 1 \\
\hline Jumlah Responden & 2 & 9 & 8 & 11 & 30 \\
\hline
\end{tabular}

Sumber : Data primer diolah, 2021

Berdasarkan Tabel 4, dapat diketahui bahwa penggunaan kredit untuk usaha tani responden lebih banyak pada persentase $<40 \%, 16$ responden menggunakan kredit untuk keperluan rumah tangga, dengan 10\%-40\% dari kredit yang diterima responden, dan $60 \%-79 \%$ dari 9 responden menggunakan kredit untuk kebutuhan sekolah anak dengan $10 \%-30 \%$ dari kredit yang diterima oleh responden, sedangkan yang menggunakan kredit untuk usahatani $100 \%$ hanya ada 5 responden. Hal ini dikarenakan penggunaan kredit lebih banyak digunakan untuk kebutuhan sehari-sehari atau kebutuhan lainnya daripada kredit digunakan seutuhnya utuk pengembangan budidaya cabai rawit. 
Tabel. 5 Hubungan antara perolehan kredit dengan hambatan memperoleh kredit.

\begin{tabular}{ccccc}
\hline \multirow{2}{*}{$\begin{array}{c}\text { Persentase penggunaan } \\
\text { kredit untuk usahatani }\end{array}$} & \multicolumn{3}{c}{ Penggunaan lain kredit } & \multirow{2}{*}{ Jumlah } \\
\cline { 2 - 4 } & $\begin{array}{c}\text { Tidak ada } \\
<10 \%\end{array}$ & $\begin{array}{c}\text { Kebutuan RT } \\
(10 \%-40 \%)\end{array}$ & $\begin{array}{c}\text { Sekolah anak } \\
(10 \%-30 \%)\end{array}$ & Responden \\
\hline $100 \%$ & 4 & 0 & 1 & 5 \\
$80-99 \%$ & 0 & 4 & 1 & 5 \\
$60-79 \%$ & 1 & 4 & 2 & 7 \\
$40-59 \%$ & 0 & 2 & 3 & 5 \\
$<40 \%$ & 0 & 6 & 2 & 8 \\
\hline Jumlah Responden & 5 & 16 & 9 & 30 \\
\hline
\end{tabular}

Sumber : Data primer diolah, 2021

Berdasarkan Tabel 5 dapat dilihat bahwa hubungan perolehan kredit dengan hambatan memperoleh kredit mempunyai hubungan yang signifikan. Artinya responden yang menyatakan perolehan kredit biasa dan sulit, karena mereka memperoleh hambatan dalam hal urusan bertele-tele dan syarat pndukung kredit. Hambatan utama untuk memperoleh kredit adalah urusan bertele-tele. Hal ini dapat dilihat dari 30 responden ada 11 responden menyatakan urusan berteletele merupakan hal yang sering terjadi dalam permohonan kredit terhadap petani, salah satu alasan yang sering terjadi karena hasil panen yang tidak menentu membuat pihak pemeberi kredit bertele-tele, sehingga menghabiskan waktu dalam pengurusan permohonan.

Tabel 6. Hubungan penggunaan kredit dengan perubahan pendapatan.

\begin{tabular}{ccccc}
\hline \% Penggunaan kredit & \multicolumn{3}{c}{ Perubahan pendapatan } & Jumlah \\
\cline { 2 - 4 } Untuk usahatani & Tinggi & Tetap & Kurang & Responden \\
\hline $100 \%$ & 4 & 0 & 0 & 4 \\
$80 \%-90 \%$ & 3 & 0 & 0 & 3 \\
$60 \%-79 \%$ & 4 & 0 & 0 & 4 \\
$40 \%-59 \%$ & 7 & 6 & 0 & 13 \\
$<40 \%$ & 5 & 1 & 0 & 6 \\
\hline Jumlah responden & 23 & 7 & 0 & 30 \\
\hline
\end{tabular}

Sumber : Data primer diolah, 2021

Berdasarkan Tabel 6 bahwa hubungan antara persentase penggunaan kredit dengan perubahan pendapatan dapat dilihat dari 30 responden yaitu pendapatan yang menjadi lebih tinggi dari sebelumnya lebih banyak menggunakan pinjaman kredit $40 \%$ $59 \%$ dari penggunaan kredit $100 \%$ untuk usaha budidaya cabai rawit dibandingkan penggunaan kredit di bawah $40 \%$, untuk usahatani budidaya cabai. Sedangkan perubahan pendapatan yang masih tetap 
masih ada walaupun responden sudah memperoleh kredit, ini disebabkan masih tahap pemula, dan juga penggunaan lain dari kredit tersebut. Dapat disimpulkan bahwa hubungan antara persentase penggunaan pinjaman kredit ada hubungan yang signifikan dengan perubahan pendapatan. Ini disebabkan penggunaan pinjaman kredit tidak seluruhnya untuk usaha budidaya cabai, karena kebanyakan pinjaman kredit dipergunakan untuk usaha lain. Berdasarkan hasil survey lapangan perubahan pendapatan petani cabai rawit dari 30 responden rata rata meningkat sampai $80 \%$.

\section{Hasil analisis regresi}

$$
\begin{gathered}
\boldsymbol{Y}=\boldsymbol{a}+\boldsymbol{b} \mathbf{1} \boldsymbol{x} \mathbf{1}+\boldsymbol{b} \mathbf{2} \boldsymbol{x} \mathbf{2}+\boldsymbol{b} \mathbf{3} \boldsymbol{x} \mathbf{3} \\
y=-41905+-493 x 1+566 x 2+183866
\end{gathered}
$$

Berdasarkan hasil estimasi diatas dapat ditentukan bahwa Koefisien regresi modal sendiri (X1) -493 mempunyai pengaruh negatif terhadap perubahan tingkat pendapatan, namun tidak signifikan. Hal ini dikarenakan modal sendiri petani hanya dalam bentuk tanah perkebunan sedangkan bibit yang bagus, pupuk, dan pestisida dibiayai oleh sebagian besar pinjaman kredit pertanian.

Koefisien regresi pinjaman kredit pertanian (X2) 566 mempunyai pengaruh positif terhadap perubahan tingkat pendapatan dan signifikan. besarnya pengaruh variabel bebas X2 (pinjaman kredit pertanian) terhadap perubahan tingkat pendapatan petani cabai rawit berpengaruh positif atau dapat dikatakan jika pinjaman kredit pertanian semakin tinggi maka kesempatan untuk mengembangkan usaha budidaya cabai rawit.

Dari hasil perhitungan koefisen regresi luas lahan (X3) 183.866 bahwa besarnya pengaruh variabel bebas X3 (luas lahan) terhadap perubahan tingkat pendapatan petani cabai berpengaruh positif atau dapat dikatakan jika luas lahan pertanian semakin luas maka semakin besar kesempatan petani cabai untuk mengembangkan usaha mereka dan semakin besar hasil produksi yang didapat dari luas lahan yang semakin luas. Namun jika pengolahan lahan kurang maksimal akan menyebabkan perubahan pendapatan berkurang ataupun tetap tidak ada perubahan. Menurut Simutorang (2013) pada penelitian tentang kelapa sawit, Koefisien regresi luas lahan mempunyai pengaruh positif terhadap perubahan tingkat pendapatan dan signifikan. Artinya jika luas lahan pertanian meningkat atau naik 1.000 (ceteris paribus) maka akan 
meningkatkan pendapatan. Tingkat pendapatan pada penelitian kali ini sebesar Rp183.866 (dalam Ha) atau Rp183866 x $1000=\mathrm{Rp} 183.866 .000$.

Koefisien determinasi $\mathrm{R}^{2}$ menunjukkan 0,734 artinya secara bersamaan atau serentak variabel modal sendiri (X1), pinjaman kredit (X2), dan luas lahan (X3) mampu memberikan penjelasan variasi tingkat pendapatan sebesar $73,4 \%$ dan sisanya sebesar $26,6 \%$ dijelaskan oleh variabel yang tidak disertakan dalam model estimasi.

\section{KESIMPULAN}

Petani cabai yang melakukan pinjaman kredit diharapkan dapat membangun atau meningkatkan pendapatan dan tingkat kesejahteraan para debiturnya yang berasal dari sektor pertanian. tentunya dengan memanfaatkan kredit yang diterima secara efisien untuk usaha yang dapat meningkatkan produktifitas pertanian. kondisi yang tercermin dari penghasilan setelah menerima pinjaman kredit untuk menjalankan usaha masih ada debitur yang berstatus diragukan dan macet atau tidak $100 \%$ berstatus lancar. Ada kemungkinan kondisi ini timbul karena beberapa debitur menggunakan kredit bukan untuk pengembangan usaha taninya tetapi untuk konsumsi yang bukan membantu produktifitas budidaya cabai.. Misalnya untuk biaya sekolah anak-anaknya, kebutuhan rumah tangga, dan konsumsi lainnya. Dari 30 responden pendapatannya $80,00 \%$ penghasilannya meningkat setelah meminjam kredit dan $20,00 \%$ responden pendapatannya tetap sama atau tidak mengalami perubahan.

\section{DAFTAR PUSTAKA}

Anshori, Abdul Ghofur. 2018. Perbankan Syariah di Indonesia. Yogyakarta: UGM Press.

Hidayat, M.R. dan Komarudin, P. 2018. Penanganan Non-Performing finance dalam akad Musyarakah di Bank Kalsel Syariah. Jurnal Studi Ekonomi, 9(1): 1-9.

Andrie B.M. 2021. Optimalisasi Pendapatan Petani Cabai Merah Dengan Diversifikasi Usahatani. Mimbar Agribisnis Jurnal Pemikiran Masyarakat Ilmiah Berwawasan Agribisnis. 7(1): 25426.

Badan Pusat Statistik dan Departemen Pertanian. 2019. Buku Pedoman Pengumpulan dan Pengolahan Data Tanaman Pangan. Jakarta: BPS dan Deptan.

Kustiari R. 2007. Perkembangan Pasar Kopi Dunia dan Implikasinya Bagi Indonesia [jurnal]. Bogor (ID): Forum Penelitian Agro Ekonomi, 25(1): 43-45

Soekartawi. 2003. Teori Ekonomi Produksi dengan Pokok Bahasan Analisis CobbDouglas. Jakarta: PT RajaGrafindo Persada. 